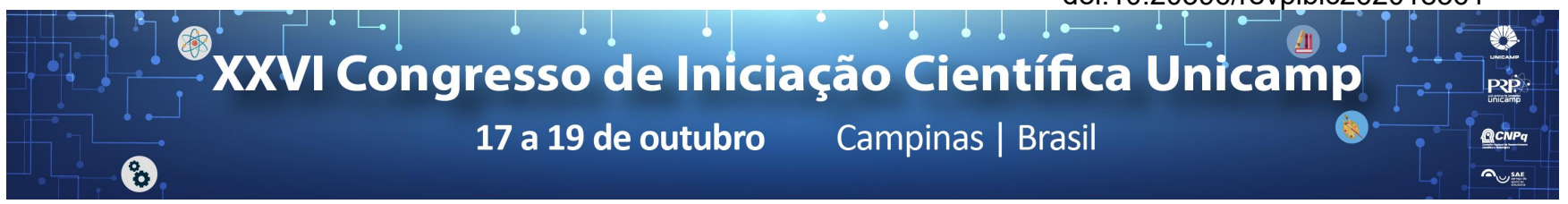

\title{
MODELAGEM APLICADA A BIOMECÂNICA DE ÁRVORES
}

\author{
Douglas P. Moraes*, Raquel Gonçalves, Mônica Ruy, Willian M. Vicente
}

\section{Resumo}

A análise de risco de queda de árvores é, atualmente, tema de grande interesse. Essa análise envolve conhecimentos multidisciplinares, dentre eles de biologia e de engenharia. Através do estudo da biomecânica, pode-se aliar aspectos biológicos - características de crescimento, anatomia das árvores e ataques de agentes biodeteriadores - ao comportamento estrutural desses indivíduos, que crescem em busca do equilibrio. De acordo com princípios da engenharia, a análise de uma estrutura deve levar em conta três aspectos fundamentais: as propriedades do material, a geometria da estrutura e as cargas atuantes. Assim, a presente pesquisa de Iniciação Científica teve como objetivo propor e testar modelo estrutural, através de programa computacional, que represente, de forma simplificada, o esquema estático de uma árvore, considerando também as ações que atuam sobre ela. Foi desenvolvido um modelo 3D através do método de elementos finitos. Dados médios de diâmetros, de altura e de angulação entre as ramificações de árvores foram utilizados para a determinação da geometria e do carregamento (peso próprio) atuante no modelo. Para simular o comportamento mais próximo do real, foram utilizadas as propriedades mecânicas da madeira saturada, obtidas em outras pesquisas do LabEND, adotando-se a consideração de ortotropia do material (9 constantes elásticas).

Palavras-chave: análise de risco de queda, arborização urbana, modelo 3D de árvore.

\section{Introdução}

As mudanças climáticas e os eventos extremos resultantes das mesmas têm ocasionado grande número de quedas de árvores, muitas vezes com resultados trágicos. Assim, a análise do risco de queda de árvores é, atualmente, tema fundamental em termos de segurança.

Esta análise envolve aspectos de biologia e de Engenharia. Dentre os aspectos biológicos estão o conhecimento das características de crescimento e de anatomia, e a suscetibilidade a ataques de agentes biodeterioradores. Dentre os aspectos de engenharia estão o conhecimento do comportamento e de propriedades mecânicas da madeira saturada proveniente das diferentes regiões que compõe a árvore (fuste, galhos e raízes), de estática e estabilidade das estruturas, de esforços normais e cisalhantes que atuam nesse elemento estrutural, dentre outros, já que a árvore é uma estrutura sujeita a diferentes tipos de carregamentos. Dessa forma, com a utilização de métodos de elementos finitos e uso do software de simulação para engenharia, esta pesquisa teve por objetivo simular, de forma simplificada, o esquema estático e o respectivo comportamento estrutural de uma árvore.

\section{Resultados e Discussão}

O trabalho foi realizado utilizando características de 3 espécies (Handroanthus pentaphylla, Schinus molle L., Schinus terebinthifolia Raddi). Dados médios de geometria (diâmetros, alturas, angulações e conicidade), de propriedades físicas (densidade) e de propriedades mecânicas (9 constantes elásticas e resistência) foram obtidos de pesquisas paralelas do grupo.

Para a simulação simplificada, a árvore foi representada apenas por seu fuste (sem galhos) - Figura 1 -, composta de uma série de elementos cilíndricos diferindo em diâmetro ao longo do seu comprimento, com uma base que simula o engastamento do fuste no solo.

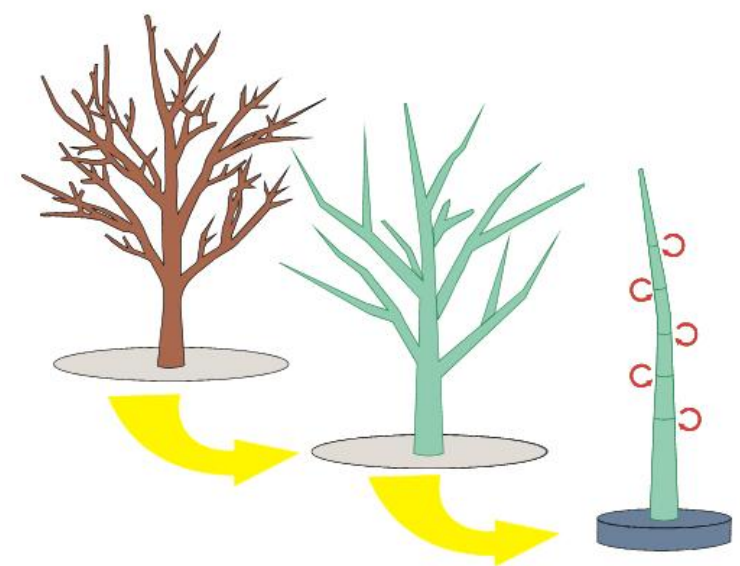

Figura 1. Modelo simplificado de uma árvore

Considerando a arquitetura da espécie e as características dos galhos (dimensões, angulação e conicidade), foram calculados momentos resultantes dos galhos em diferentes pontos do fuste. A carga de vento, calculada de acordo com critérios da NBR 6123 , foi também simulada de forma simplificada, considerando sua resultante no centro de gravidade da copa.

\section{Conclusões}

Foi possível obter um modelo simplificado que representa o comportamento estrutural de uma árvore frente aos esforços atuantes, os quais devem ser validados utilizando ensaios mecânicos (Pulling test) em árvores.

\section{Agradecimentos}

Ao CNPq e CAPES, pelas bolsas de estudos (IC e doutorado). 